\title{
Initial offspring size mediates trade-off between fecundity and longevity in the field
}

\author{
Halil Kesselring ${ }^{1}$, Rebecca Wheatley ${ }^{1}$, Dustin J. Marshall ${ }^{1,2, *}$ \\ ${ }^{1}$ School of Biological Sciences, The University of Queensland, Brisbane 4072, Australia \\ ${ }^{2}$ School of Biological Sciences, Monash University, Clayton 3800, Australia
}

\begin{abstract}
An understanding of the effects of intraspecific variation in offspring size is important from both an ecological and an evolutionary perspective. While the relationship between offspring size and overall offspring performance is key, most studies are restricted to examination of the effects of offspring size on early life-history stages only, and too few have examined the effects of offspring size throughout the life history. Here, we examine the effects of offspring size on postmetamorphic survival, growth, and fecundity under field conditions for the polychaete Janua sp. Larger offspring became larger adults and had higher levels of fecundity than those from smaller offspring, though the effect on fecundity was weaker and more variable over different experimental runs. Adults derived from larger larvae had shorter lifespans than adults derived from smaller larvae. Our results suggest that the maternal effect of offspring size can influence the frequently observed trade-off between longevity and fecundity. Future studies should seek to measure the effects of offspring size over as much of the life history as possible in order to avoid misestimating the relationship between offspring size and fitness.
\end{abstract}

KEY WORDS: Maternal effect $\cdot$ Egg size $\cdot$ Larval quality

\section{INTRODUCTION}

Evolutionary ecologists have long sought to understand the causes and consequences of variation in offspring size in marine organisms (Thorson 1936, Laptikhovsky 2006, Marshall \& Morgan 2011). Among species, there is a remarkable degree of variation in offspring size (Emlet et al. 1987), but offspring size variation within species is of more interest from both an evolutionary and an ecological perspective (Bernardo 1996). Evolutionarily, selection acts upon within-population variation in offspring size (Sprenger et al. 2010). Ecologically, variation in offspring size within and among populations will affect population dynamics (Benton et al. 2005). While offspring size affects the fitness of both mothers and offspring, theory predicts that selection will act to maximize maternal fitness (Vance 1973, Smith \& Fretwell 1974). Thus, mothers with limited resources for reproduction (whether that be energy, brood space, or time to provision) must produce either many small offspring or fewer but larger offspring. Generally, it is thought that larger offspring perform better than smaller offspring, and so the maternal fecundity costs associated with producing larger offspring should be offset by each offspring performing better (Marshall \& Keough 2007). The specific offspring size that maximizes maternal fitness, however, will depend strongly on the relationship between offspring size and offspring fitness (Bernardo 1996), and estimates of this relationship, particularly in the field, remain rare.

Over the past $30 \mathrm{yr}$, numerous empirical observations of the effects of offspring size on offspring performance have accumulated (Clutton-Brock 1991, 
Fox \& Czesak 2000, McCormick 2006, Marshall \& Keough 2007), but very few studies directly examine the relationship between offspring size and close proxies of fitness under field conditions. This dearth of studies may reflect the difficulty associated with collecting measures of performance that are likely to scale well with fitness in the field. Thus, most of the studies on the effects of offspring size either gather good measures of fitness but are restricted to the laboratory, or are done in the field but are restricted to earlier lifehistory stages (Marshall \& Keough 2007). Both approaches have limitations. Several studies have shown that the offspring size-fitness relationship is strongly affected by the environment, and unless laboratory conditions adequately replicate field conditions (Fox 2000, Monro et al. 2010), laboratory approaches risk misestimating the offspring sizefitness relationship. Similarly, field studies that are restricted to early performance measures alone may over- or underestimate the effect of offspring size on offspring performance. Studies indicate that offspring size effects can both intensify or lessen over ontogeny, and so both scenarios seem plausible (Lindholm et al. 2006, Marshall \& Keough 2009, Dias \& Marshall 2010). A more reliable estimate of the effects of offspring size on fitness overall is to determine the effect of offspring size on lifetime reproductive success, but such studies are exceedingly rare.

While the effects of offspring size on offspring performance have been estimated in many species, very few estimate the effects of offspring size on fecundity. As such, our ability to generalize about the effects of offspring size on fitness remains limited. The lack of studies estimating the offspring size-fitness relationship makes it difficult to predict whether variation in offspring size has lasting, multi-generational effects (Marshall et al. 2003, Benton et al. 2005), or only transient impacts of no consequence (Lindholm et al. 2006). Such predictions have important consequences for estimating the importance of maternal effects and managing exploited species (Berkeley et al. 2004, Marshall et al. 2010). Overall then, more measures of the relationship between offspring size and offspring fecundity are needed. In the present study, we estimate the relationship between offspring size and subsequent survival, and between survival and reproduction under field conditions in the spirorbid tube worm Janua sp. We performed multiple runs to determine the spatial and temporal consistency of offspring size effects.

\section{MATERIALS AND METHODS}

\author{
Study location and species
}

The study was done during the austral winter of 2010 at Manly Boat Harbor (Brisbane, Australia; $27.467^{\circ} \mathrm{S}, 153.183^{\circ} \mathrm{E}$ ). The harbor is sheltered by a breakwater and consists of floating docks. The subtidal fouling community comprises $>30$ sessile marine invertebrate species, including colonial and solitary ascidians, bryozoans, tubiculous polychaetes, barnacles, and sponges.

Spirorbids are a clade of small, filter-feeding polychaetes, all of which brood their embryos in a variety of brooding modes. The focal species of the present study (presumably Janua pagenstecheri or $J$. neodexiospira) broods in an opercular brood chamber. As worms become sexually mature, the opercular tentacle grows into a chamber in which eggs are deposited. Approximately $5 \mathrm{~d}$ after eggs have been deposited, the brood chamber opens at its base and larvae are released. Spawning can be encouraged by maintaining brooding adults in constant darkness for $24 \mathrm{~h}$ before exposing them to bright light. Larvae are competent to settle upon release, and in our study, the majority of larvae settled within 20 min in the laboratory.

\section{Collecting animals, measuring offspring size, and larval settlement}

Adult spirorbids were collected from the harbor on acetate sheets attached to PVC backing plates (400 $\mathrm{mm} \times 400 \mathrm{~mm} \times 12 \mathrm{~mm}$ ) suspended $\sim 1 \mathrm{~m}$ below the surface. After $5 \mathrm{wk}$, sheets were returned to the laboratory and individuals with mature embryos were detached from the sheets and each placed in their own well in a 24 -well tissue culture plate with $2 \mathrm{ml}$ filtered seawater (FSW).

On the following day, these worms spawned and offspring were collected and their size measured. Individual larvae were collected with a pipette and each put in a drop of $1 \mu \mathrm{l}$ FSW in an observation chamber. Observation chambers were made of a microscope slide and a large glass cover slip spaced away from the slide with a strip of plastic on either side just so much as to restrict larval movement to a 2-dimensional plane, thereby guaranteeing that larvae were always positioned with their dorsal side facing upwards. Microscope slides and cover slips as well as pipette tips were coated in Sigmacote ${ }^{\circledR}$ (SL2, Sigma-Aldrich). Digital photographs were made of 
the larvae under an Olympus CX41 dark-field microscope at a 10-fold magnification with a TUCSEN ix90 digital camera (Tucsen Imaging Technology). Larvae were held in observation chambers for no longer than $5 \mathrm{~min}$, but can survive in them for longer than $12 \mathrm{~h}$ (H. Kesselring pers. obs.). Larval size was measured as area using the free software ImageJ 1.42q for PC (available at http://rsb.info.nih.gov/ij). Area is presumably a good measure of size, as larval depth is unlikely to negatively covary with larval area. Once photographed, larvae were put into a large drop of FSW in a Petri dish and allowed to settle for $4 \mathrm{~h}$. Young settlers were then deployed at the harbor on the same evening. We measured a total of 863 larvae collected from $>50$ different mothers, with a range of offspring sizes collected from each mother. We conducted 6 different experimental runs across a period of several months, and each run was deployed into a different location in the field.

\section{Measuring growth and fecundity}

After $2 \mathrm{wk}$, our focal worms were retrieved from the field and their size measured, again by taking a digital photograph under a dissecting microscope and measuring the area of the worm. At this stage the worms had not started to grow away from the substrate as older worms frequently do, and so their 2dimensional area as viewed from above was a good measure of overall size.

After another $2 \mathrm{wk}$ in the field, the worms began to reproduce. At this time, focal individuals already experienced intense competition from other sessile organisms such as ascidians, bryozoans, and sponges. To estimate reproduction, we returned the worms to the laboratory for spawning. Therefore, each worm was detached from its Petri dish and put into a new Petri dish with $4 \mathrm{ml}$ FSW that was fitted with a circle of sheeting on which larvae could settle. On the next day, worms had spawned and we were able to estimate fecundity by counting the number of larvae that were released and that had settled. The focal adults were then glued back to their original Petri dish using $1 \mu$ superglue, a procedure that all individuals survived. After a further $20 \mathrm{~d}$ in the field, we again brought in the focal worms to measure fecundity at a later stage in their lives. Based on brooding periods and observation, we suspect that the worms produced some offspring in between sampling periods, but no worms reproduced after the second sampling period, as all worms died of parasitic infections afterwards (the rest of the population at our site, i.e. non-experimental individuals, suffered similarly high rates of mortality and parasitic infection). Thus, our estimates of reproduction do not represent lifetime fecundity (the ideal for studies of offspring size), but instead give 2 snapshot estimates. These 2 estimates were correlated with each other (regression: $\mathrm{R}^{2}=0.25, \mathrm{n}=44, \mathrm{p}=0.056$ ), suggesting that there was no trade-off between early and late reproduction, and that our measures probably reflect lifetime reproductive output. Because the estimation of individual growth and reproduction was time-consuming and had to be done in the laboratory, we could not measure these parameters in all of our study individuals while minimizing the time that they spent out of the field. We therefore measured performance in only a randomly selected subsample of the experimental population. We measured growth of a subsample of 624 randomly selected juveniles, fecundity at first reproduction of a randomly selected subsample of 118 individuals, and fecundity of all the individuals that survived to the last round of reproduction (44 individuals). These 44 individuals came from 30 different mothers.

\section{Statistical analysis}

Analyses on size and reproduction were done with the general linear model function in Systat (version 12), where Larval size was a continuous variable and Run was a categorical random effect (i.e. analysis of covariance [ANCOVA]). We were unable to include Run in the model for the analysis of fecundity at the last reproduction because covariate ranges differed among runs (Quinn \& Keough 2002).

Very few $(<5 \%)$ individuals died during the first $4 \mathrm{wk}$ in the field, but $>60 \%$ died between the first round of reproduction and the last round of reproduction. We therefore estimated the effect of larval size on survival between rounds of reproduction with logistic ANCOVA.

\section{RESULTS}

\section{Larval size variation}

The overall mean size of all measured larvae was $0.016 \mathrm{~mm}^{2}$. The average coefficient of variation in larval size was $7.9 \%$ within broods and $11.9 \%$ among broods from different mothers. 


\section{Effects of larval size on growth}

Larval size was a good predictor of juvenile size: every $0.001 \mathrm{~mm}^{2}$ increase in larval size was predicted to increase juvenile size by $\sim 0.029 \mathrm{~mm}^{2}$ after $2 \mathrm{wk}$ in the field (Table 1; linear regression equation: Juvenile size $=29.32 \times$ Larval size -0.012 ). The relationship between larval size and juvenile size varied significantly among runs, but the relationship between offspring size and juvenile size remained positive for all runs (Fig. 1).

\section{Effects of larval size on fecundity}

Our analyses indicated that the effect of larval size on fecundity at the first reproduction varied among experimental runs (Run $\times$ Larval size interaction: $F_{5,106}=2.11, \mathrm{p}=0.07$ ). In Runs 1,3 , and 6, there was a significantly positive relationship between larval size and fecundity $\left(F_{1,47}=7.44, \mathrm{p}=0.009\right.$; Fig. 2$)$, but in Runs 2, 4, and 5, there was no significant relation- ship $\left(F_{1,63}=0.346, \mathrm{p}=0.559\right)$. For those individuals that survived to reproduce again, fecundity was greater than in the first round of reproduction (paired $t$-test: $\left.t_{43}=3.71, \mathrm{p}=0.001\right)$. Fecundity at the last reproduction was also affected by larval size, with larger individuals producing more offspring than smaller individuals $\left(\mathrm{R}^{2}=0.103, F_{1,43}=4.92, \mathrm{p}=0.032\right.$; Fig. 3), but this result should be interpreted with caution, given that we could not include Run in our analysis.

Table 1. Janua sp. ANCOVA examining the effect of offspring size and experimental run on the size of juveniles after $2 \mathrm{wk}$ in the field

\begin{tabular}{|lccrr|}
\hline & df & MS & $F$ & \multicolumn{1}{c|}{ p } \\
\hline Larval size & 1 & 0.669 & 11.339 & 0.001 \\
Run & 5 & 0.028 & 2.050 & 0.070 \\
Interaction & 5 & 0.059 & 4.393 & 0.001 \\
Error & 612 & 0.013 & & \\
\hline
\end{tabular}

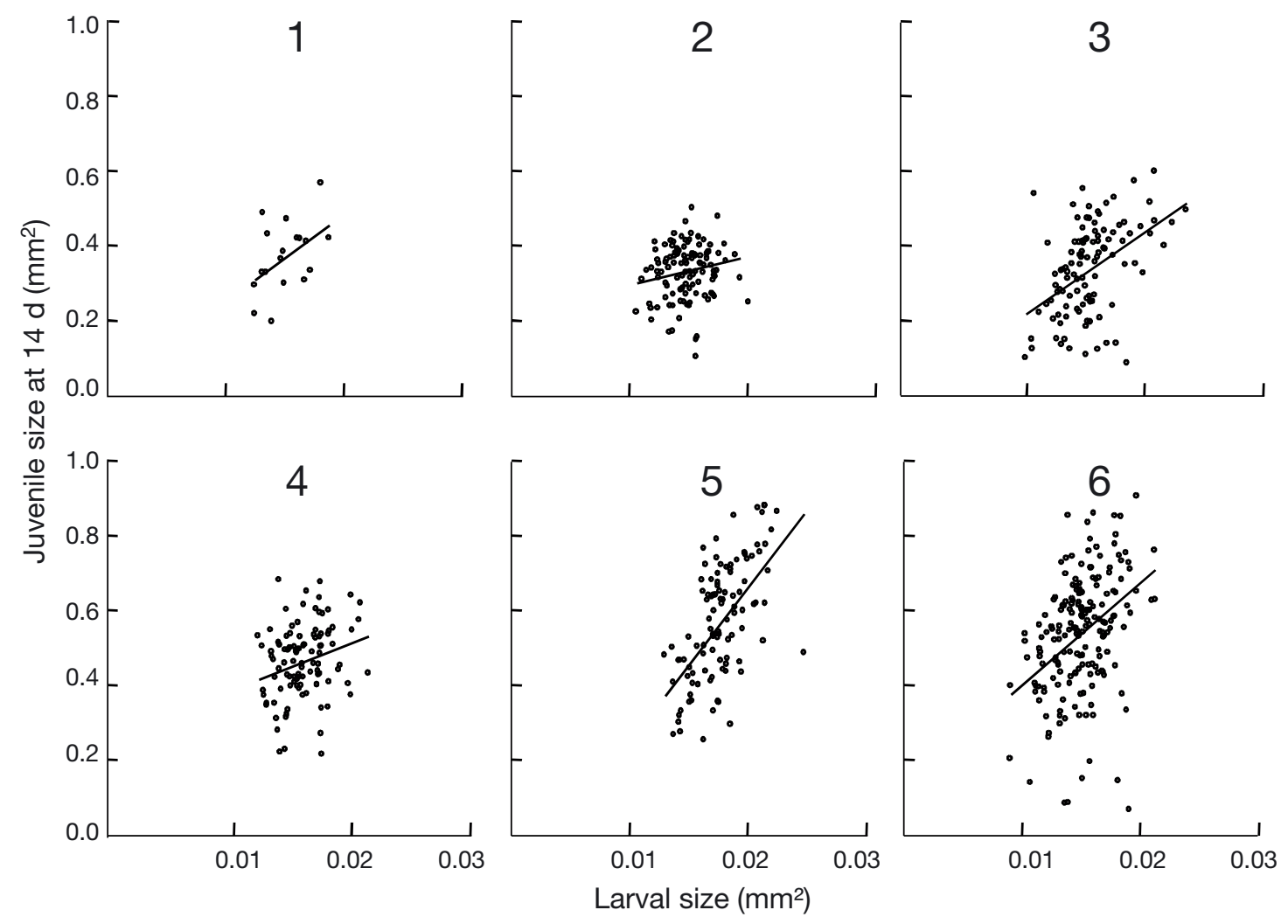

Fig. 1. Janua sp. Relationship between initial offspring size and subsequent juvenile size after 2 wk in the field across 6 experimental runs (numbers 1 to 6 at the top of the panels). Each point represents an individual worm, and each line is the line of best fit for that run 


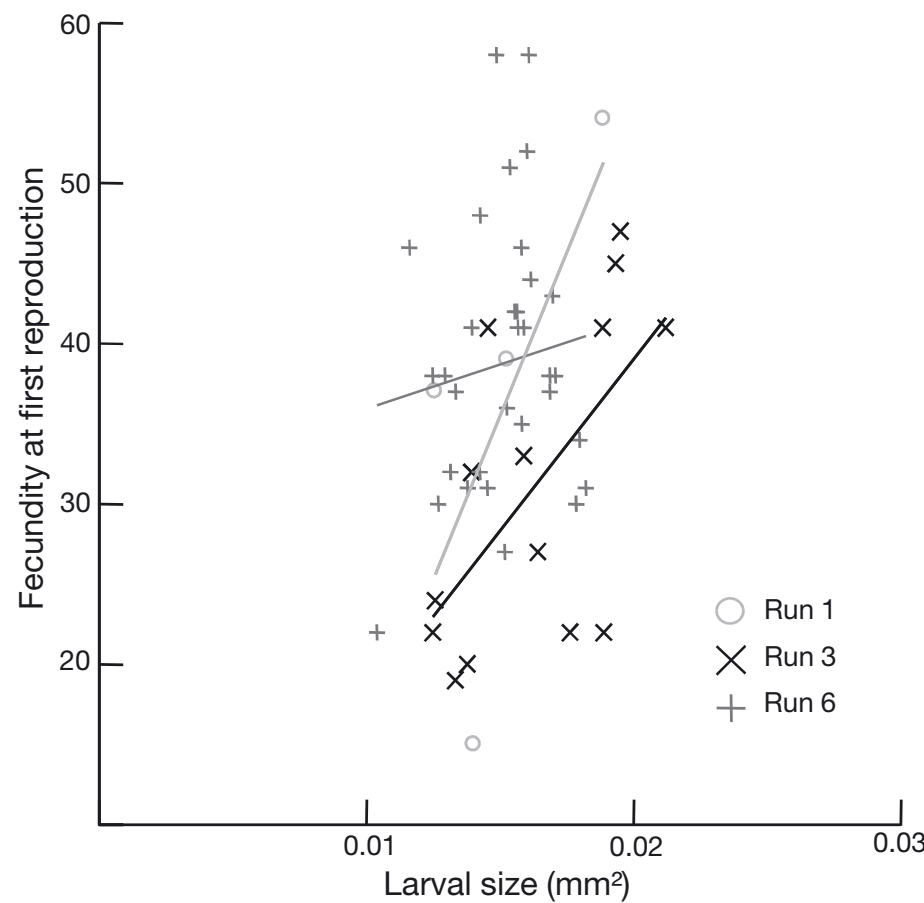

Fig. 2. Janua sp. Relationship between initial offspring size and early fecundity in the field across 3 experimental runs where offspring size had an effect. Each point represents an individual worm, and each line represents the line of best fit for that run

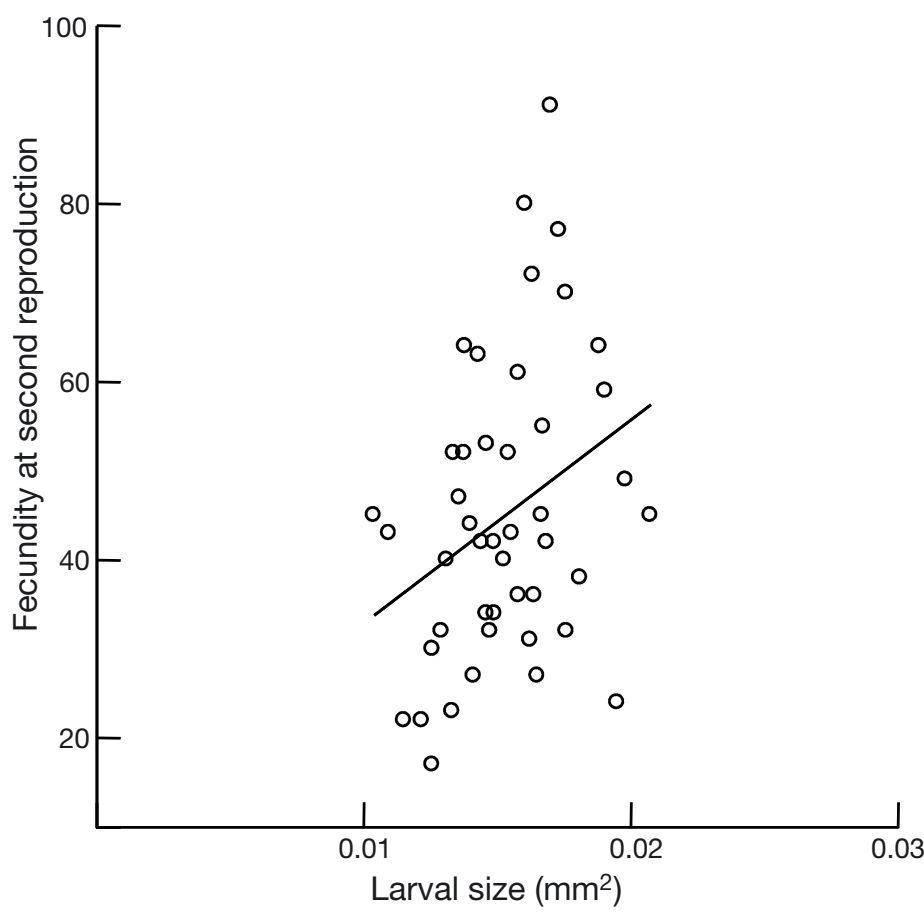

Fig. 3. Janua sp. Relationship between initial offspring size and late fecundity in the field. Note that data are pooled across all experimental runs. Each point represents an individual worm, and the line represents the line of best fit across all runs

\section{Effects of larval size on survival}

Survival between rounds of reproduction was negatively affected by larval size: those individuals that were larger as larvae were more likely to die between reproductive bouts than those individuals that were smaller as larvae (logit equation: Probability of surviving $=-278 \times$ larval size $+2.402 ; \chi^{2}=6.48$, $\mathrm{df}=1, \mathrm{p}=0.011$ ). Individuals that started life $0.001 \mathrm{~mm}^{2}$ larger than the mean larval size were $\sim 30 \%$ more likely to die between reproductive bouts.

\section{DISCUSSION}

The effects of larval size on the post-metamorphic performance of Janua sp. varied across experimental runs, and across the life history within runs. Generally, individuals that were larger as larvae grew to a larger size after $2 \mathrm{wk}$ in the field and sometimes had higher levels of fecundity, but surprisingly these individuals were also more likely to die in the period between the first round of reproduction and the last.

Our observation of variable effects among experimental runs is in keeping with most offspring size studies that replicate in time and space (Moran \& Emlet 2001, Marshall \& Keough 2008). Increasingly, it seems that the offspring size-performance relationship is strongly affected by the local environment, and variability in the offspring size-performance relationship is the rule rather than the exception (Johnston \& Leggett 2002, Heath et al. 2003). This inconsistency in the offspring size-performance relationship may explain why some mothers produce smaller offspring despite these offspring often having lower performance. If on occasion there is no benefit of producing larger offspring (as indicated by the present study), mothers that produce smaller offspring will received the same per-offspring fitness return while also maximizing the number of larvae that they produce (Smith \& Fretwell 1974). This variability in the offspring size-performance relationship may also result in selection for mothers that produce a range of offspring sizes within a clutch (i.e. diversified bet-hedging; Marshall et al. 2008)

Our most qualitatively consistent finding was that larger larvae became much larger adults after $2 \mathrm{wk}$ in the field relative to smaller larvae. The mechanism underlying the effect of larval size on juvenile size is unknown, but it could be that larger larvae result in larger settlers with larger feeding structures (Kosman \& Pernet 2011). Small, initial differences in the size of feeding structures can result in very different 
growth rates in colonial species (Wendt 1996, 1998), but we are unaware of similar effects being reported in solitary species such as Janua sp. From an ecological perspective, regardless of the cause of the effect, it appears that variation in initial larval size will result in variation in the size of individuals after $2 \mathrm{wk}$ in the field. Increasingly, it appears that variation in the quality of settlers can be substantial and that this can affect the subsequent performance of recruits (Phillips 2002, Phillips \& Gaines 2002).

The effects of larval size on reproduction were both weaker and qualitatively less consistent than the effects of larval size on growth. This decrease in the strength of the effect could be driven by a number of (non-mutually exclusive) factors. First, laboratory studies have demonstrated that maternal effects (of which offspring size effects are a subset) can decrease over time due to an increase in the influence of extrinsic, environmental factors or intrinsic 'compensatory growth effects' (Falconer 1981, Lindholm et al. 2006). It has been proposed that compensatory growth effects are more likely to be observed in the benign conditions of the laboratory (Marshall et al. 2010). Indeed, offspring size effects can be remarkably persistent under more realistic, harsher conditions (Plaistow et al. 2006) and can sometimes even strengthen over time in the field (Dias \& Marshall 2010). Interestingly, of those studies that find persistent effects of offspring size over time (Marshall et al. 2003, Dias \& Marshall 2010, Rius et al. 2010), most are on species that are intermediate-to-strong competitors (but see Jacobs \& Sherrard 2010). In contrast, Janua sp. is an early colonist and poor competitor in our community - all of our experimental individuals had died after 6 wk in the field (more generally, very few naturally settled individuals survive beyond 2 mo in the field; D. J. Marshall unpubl. data). It may be that offspring size effects are more persistent in more competitive species because they are better able to overcome environmental swamping effects from other species, but this prediction requires testing. Alternatively, the less consistent effects of offspring size on reproduction in our study could be driven by a simple lack of statistical power - by the last census period, $<10 \%$ of the focal individuals remained. Nevertheless, fecundity in the final reproductive bout was positively correlated with initial larval size, suggesting that offspring size effects have the potential at least to persist in this species.

In contrast to the positive effects of offspring size on growth and reproduction, we found that larval size negatively affected survival between reproductive bouts - individuals from larger larvae were more likely to die than individuals from smaller larvae. Other studies have found negative effects of offspring size on offspring performance (Kaplan 1992, Marshall et al. 2002, Marshall \& Keough 2004, Dibattista et al. 2007), but such findings seem to be in the minority. The negative effect of offspring size on survival is difficult to explain. It could be that larval size affects subsequent survival negatively due to indirect effects whereby increased larval size is associated with some other trait that is directly linked to mortality. For example, larger larvae become larger juveniles and they may have higher resource requirements (e.g. food or oxygen) than smaller juveniles - as time goes on, larger juveniles may become more susceptible to competition for these resources and therefore suffer higher levels of mortality. Alternatively, because larger larvae are more likely to be more fecund as adults, the costs of increased reproduction could result in higher rates of mortality. A direct mortality cost associated with higher fecundity or size does not seem likely, however, as further data analysis indicated that there was no direct relationship between fecundity and probability of death; rather, both were related to larval size. Studies in other systems suggest that some individuals express a 'live fast, die young' phenotype such that offspring size affects this trade-off in an indirect way (Robinson et al. 2006, Bonduriansky et al. 2008), and it could be that offspring size plays a role in the expression of such a phenotype. Certainly in other systems, individual quality effects (here, offspring size) can influence the trade-off between longevity and reproduction (Weladji et al. 2008), but we are unaware of any other studies drawing a link between offspring size and the longevity-fecundity trade-off. Alternatively, genetic effects could be driving the pattern: a recent study found that in an internally fertilizing ascidian (i.e. an organism with a similar mode of reproduction to our study species), paternity affects larval size (Hammerschmidt et al. 2011) — it could be that in Janua sp., larval size also reflects paternity. If so, then genes that result in larger larvae could cause higher rates of mortality after initial reproduction (Bonduriansky et al. 2008). Clearly, the effects of larval size on post-metamorphic performance are more complex than a simple presence of a positive effect versus the absence of a positive effect. The relationship between offspring size and fitness is not simply asymptotic in this species; rather, it is likely to be bell-shaped whereby both the smallest and largest offspring have the lowest fitness due to lower fecundity and lower survival respectively. When such a relationship occurs, theory predicts that 
mothers should produce a range of offspring sizes to cope with environmental uncertainty (Marshall et al. 2008), and we certainly observed high levels of offspring size variation both within and among broods of offspring.

Regardless of the cause of the negative effects of larval size on survival, from a maternal provisioning perspective, the relative benefits of producing larger offspring will strongly depend on the probability and timing of mortality (McGinley et al. 1987). If conditions result in offspring being likely to survive past the first round of reproduction, then selection should favor smaller offspring because smaller offspring are more likely to reproduce multiple times (albeit with lower fecundity in any one round). Alternatively, if conditions are such that survival beyond the first round of reproduction is extremely unlikely, then selection should favor mothers that produce larger offspring, because larger offspring are more likely to have the greatest fecundity in the first reproductive bout alone. Overall, our findings suggest that a focus on one early performance metric alone (e.g. Marshall \& Keough 2008) could result in the misestimation of offspring size effects, and future studies should aim to estimate the effects of offspring size on as many different life-history stages as possible.

Acknowledgements. We thank 3 anonymous reviewers whose comments improved the manuscript, and the staff at Manly Marina for giving us access to their facilities. D.J.M. was supported by grants from the Australian Research Council.

\section{LITERATURE CITED}

Benton TG, Plaistow SJ, Beckerman AP, Lapsley CT, Littlejohns $S$ (2005) Changes in maternal investment in eggs can affect population dynamics. Proc R Soc B Biol Sci 272:1351-1356

> Berkeley SA, Chapman C, Sogard SM (2004) Maternal age as a determinant of larval growth and survival in a marine fish, Sebastes melanops. Ecology 85:1258-1264

Bernardo J (1996) The particular maternal effect of propagule size, especially egg size: patterns models, quality of evidence and interpretations. Am Zool 36:216-236

Bonduriansky R, Maklakov A, Zajitschek F, Brooks R (2008) Sexual selection, sexual conflict and the evolution of ageing and life span. Funct Ecol 22:443-453

Clutton-Brock TH (1991) The evolution of parental care. Princeton University Press, Princeton, NJ

Dias GM, Marshall DJ (2010) Does the relationship between offspring size and performance change across the lifehistory? Oikos 119:154-162

Dibattista JD, Feldheim KA, Gruber SH, Hendry AP (2007) When bigger is not better: selection against large size, high condition and fast growth in juvenile lemon sharks. J Evol Biol 20:201-212
Emlet RB, McEdward LR, Strathmann RR (1987) Echinoderm larval ecology viewed from the egg. In: Langoux M, Lawrence J (eds) Echinoderm studies, Book 2. AA Balkema, Rotterdam, p 55-136

Falconer DS (1981) Introduction to quantitative genetics. Longman, New York, NY

Fox CW (2000) Natural selection on seed-beetle egg size in nature and the laboratory: variation among environments. Ecology 81:3029-3035

> Fox CW, Czesak ME (2000) Evolutionary ecology of progeny size in arthropods. Annu Rev Entomol 45:341-369

> Hammerschmidt K, Pemberton AJ, Michiels NK, Bishop JDD (2011) Differential maternal allocation following mixed insemination contributes to variation in oocyte size in a sea squirt. Mar Ecol Prog Ser 422:123-128

Heath DD, Heath JW, Bryden CA, Johnson RM, Fox CW (2003) Rapid evolution of egg size in captive salmon. Science 299:1738-1740

Jacobs MW, Sherrard KM (2010) Bigger is not always better: offspring size does not predict growth or survival for seven ascidian species. Ecology 91:3598-3608

Johnston TA, Leggett WC (2002) Maternal and environmental gradients in the egg size of an iteroparous fish. Ecology 83:1777-1791

Kaplan RH (1992) Greater maternal investment can decrease offspring survival in the frog Bombina orientalis. Ecology 73:280-288

> Kosman ET, Pernet B (2011) Intraspecific variation in larval size and its effects on juvenile lophophore size in four bryozoans. Mar Ecol Prog Ser 429:67-73

Laptikhovsky V (2006) Latitudinal and bathymetric trends in egg size variation: a new look at Thorson's and Rass's rules. Mar Ecol 27:7-14

Lindholm AK, Hunt J, Brooks R (2006) Where do all the maternal effects go? Variation in offspring body size through ontogeny in the live-bearing fish Poecilia parae. Biol Lett 2:586-589

> Marshall DJ, Keough MJ (2004) Variable effects of larval size on post-metamorphic performance in the field. Mar Ecol Prog Ser 279:73-80

- Marshall DJ, Keough MJ (2007) The evolutionary ecology of offspring size in marine invertebrates. Adv Mar Biol 53: $1-60$

Marshall DJ, Keough MJ (2008) The relationship between offspring size and performance in the sea. Am Nat 171: 214-224

> Marshall DJ, Keough MJ (2009) Does interspecific competition affect offspring provisioning? Ecology 90: 487-495

> Marshall DJ, Morgan SG (2011) Ecological and evolutionary consequences review of linked life-history stages in the sea. Curr Biol 21:R718-R725

> Marshall DJ, Styan CA, Keough MJ (2002) Sperm environment affects offspring quality in broadcast spawning marine invertebrates. Ecol Lett 5:173-176

> Marshall DJ, Bolton TF, Keough MJ (2003) Offspring size affects the post-metamorphic performance of a colonial marine invertebrate. Ecology 84:3131-3137

Marshall DJ, Bonduriansky R, Bussiere LF (2008) Offspring size variation within broods as a bet-hedging strategy in unpredictable environments. Ecology 89:2506-2517

Marshall DJ, Heppell S, Munch SB, Warner RR (2010) The relationship between maternal phenotype and offspring quality: Do older mothers really produce the best offspring? Ecology 91:2862-2873 
McCormick MI (2006) Mothers matter: crowding leads to stressed mothers and smaller offspring in marine fish. Ecology 87:1104-1109

McGinley MA, Temme DH, Geber MA (1987) Parental investment in offspring in variable environments: theoretical and empirical considerations. Am Nat 130: 370-398

Monro K, Sinclair-Taylor T, Marshall DJ (2010) Selection on offspring size among environments: the roles of environmental quality and variability. Funct Ecol 24:676-684

Moran AL, Emlet RB (2001) Offspring size and performance in variable environments: field studies on a marine snail. Ecology 82:1597-1612

Phillips NE (2002) Effects of nutrition-mediated larval condition on juvenile performance in a marine mussel. Ecology 83:2562-2574

Phillips NE, Gaines SD (2002) Spatial and temporal variability in size at settlement of intertidal mytilid mussels from around Pt. Conception, California. Invertebr Reprod Dev 41:171-177

Plaistow SJ, Lapsley CT, Benton TG (2006) Context-dependent intergenerational effects: the interaction between past and present environments and its effect on population dynamics. Am Nat 167:206-215

Quinn GP, Keough MJ (2002) Experimental design and data analysis for biologists. Cambridge University Press, Cambridge

Rius M, Turon X, Dias GM, Marshall DJ (2010) Propagule size effects across multiple life-history stages in a marine

Editorial responsibility: Roger Hughes,

Bangor, UK invertebrate. Funct Ecol 24:685-693

Robinson MR, Pilkington JG, Clutton-Brock TH, Pemberton JM, Kruuk LEB (2006) Live fast, die young: trade-offs between fitness components and sexually antagonistic selection on weaponry in Soay sheep. Evolution 60: 2168-2181

Smith CC, Fretwell SD (1974) The optimal balance between size and number of offspring. Am Nat 108:499-506

Sprenger D, Lange R, Michiels NK, Anthes N (2010) Sources of phenotypic variance in egg and larval traits in a marine invertebrate. Evol Ecol 24:185-194

Thorson G (1936) The larval development, growth and metabolism of Arctic marine bottom invertebrates compared with those of other seas. Medd Grønland 100: $1-155$

Vance RR (1973) On reproductive strategies in marine benthic invertebrates. Am Nat 107:339-352

Weladji RB, Loison A, Gaillard JM, Holand O and others (2008) Heterogeneity in individual quality overrides costs of reproduction in female reindeer. Oecologia 156: 237-247

- Wendt DE (1996) Effect of larval swimming duration on success of metamorphosis and size of the ancestrular lophophore in Bugula neritina (Bryozoa). Biol Bull (Woods Hole) 191:224-233

Wendt DE (1998) Effect of larval swimming duration on growth and reproduction of Bugula neritina (Bryozoa) under field conditions. Biol Bull (Woods Hole) 195: 126-135

Submitted: February 27, 2012; Accepted: June 6, 2012 Proofs received from author(s): September 14, 2012 